\title{
PENDAMPINGAN PROSES TRANSFORMASI SISTEM PENJAJARAN REKAM MEDIS MENGGUNAKAN TERMINAL DIGIT FILING
}

\author{
Kori Puspita Ningsih $\left.{ }^{*}\right)$; Angga Eko Pramono ${ }^{b}$; Dian Budi Santoso ${ }^{c}$; Laili Rahmatul Ilmi ${ }^{d}$ \\ Heri Hernawane
a, d, e Program Studi Rekam Medis dan Informasi Kesehatan;Universitas Jenderal Achmad Yani Yogyakarta;Jl.Brawijaya Ringroad Barat, Ambarketawang, Gamping, Sleman, DIY
$b, c$ Program Studi Manajemen Informasi Kesehatan; Universitas Gadjah Mada; Sekip Unit 1, Catur Tunggal, Depok, Sleman, DIY

\begin{abstract}
Abstrak
Puskesmas sebagai penyedia sarana pelayanan kesehatan dituntut untuk memberikan pelayanan kesehatan yang cepat, tepat dan akurat. Oleh karena itu, puskesmas harus mampu mengelola rekam medis dengan baik sehingga rekam medis dapat disediakan dengan cepat dan tepat saat dibutuhkan. Puskesmas Gondokusuman 2 Kota Yogyakarta menerapkan sistem penyimpanan berkas rekam medis berdasarkan wilayah. Adanya peningkatan signifikan pada kunjungan pasien baru dari luar daerah menyebabkan penumpukan berkas rekam medis pada satu lokasi saja. Tujuan Pengabdian Kepada Masyarakat (PKM) ini adalah melakukan transformasi sistem penjajaran rekam medis menggunakan TDF. Metode dalam kegiatan ini dengan pendekatan difusi ipteks, melalui rangkaian kegiatan penyuluhan, pelatihan dan demonstrasi sistem penjajaran rekam medis, pengadaan sarana proses transformasi sistem penjajaran berupa rak kayu serta pendampingan proses transformasi dari penjajaran rekam medis berdasarkan wilayah menjadi TDF dengan sasaran petugas rekam medis yang dilaksanakan selama 3 bulan. Hasil pengabdian ini adalah penerapan Terminal Digit Filing yang mampu menyimpan rekam medis tersebar ke dalam semua section rak penyimpanan, sehingga mampu meningkatkan efisiensi dan efektivitas kegiatan penjajaran rekam medis. Diharapkan program evaluasi dan monitoring pendampingan proses transformasi sistem penjajaran TDF dapat dilakukan pada program PKM berikutnya untuk menjamin keberhasilan proses transformasi.
\end{abstract}

Kata kunci: rekam medis; sistem penyimpanan angka akhir; sistem penjajaran

\begin{abstract}
[MEDICAL RECORD TRANSFORMATION SYSTEM ASSISTANCE USING DIGIT FILING TERMINALS] Puskesmas as a provider of health service facilities are required to provide fast, precise and accurate health services. Therefore, puskesmas must be able to manage medical records properly so that medical records can be provided quickly and precisely when needed. Puskesmas Gondokusuman 2 Yogyakarta City implements a file storage system for medical records based on regions. There is a significant increase in new patient visits from outside the area causing the accumulation of medical record files at one location only. The purpose of Community Service (PKM) is to transform the medical record alignment system using TDF. The method in this activity is the science and technology diffusion approach, through a series of outreach activities, training and demonstration of the medical record alignment system, and assistance in the transformation process from aligning medical records by region to TDF targeting medical record officers who are implemented. for 3 months. The result of this service is the application of a Digit Filing Terminal which is able to store medical records spread into all sections of storage racks, thereby increasing the efficiency and effectiveness of medical record alignment activities. It is hoped that the evaluation and monitoring program for the assistance of the TDF alignment system transformation process can be carried out in the next PKM program to ensure the success of the transformation process.
\end{abstract}

Keywords: Medical record; terminal digit filing system; the aligment system

\section{Pendahuluan}

Di bidang kedokteran dan kedokteran gigi,

*) Correspondence Author (Kori Puspita Ningsih)
E-mail: puspitakori@gmail.com rekam medis merupakan salah satu bukti tertulis tentang proses pelayanan yang diberikan oleh dokter dan dokter gigi. Rekam medis berisi data klinis pasien selama proses diagnosis dan 
pengobatan (treatment). Oleh karena itu, setiap kegiatan pelayanan medis harus mempunyai rekam medis yang lengkap dan akurat untuk setiap pasien dan setiap dokter dan dokter gigi wajib mengisi rekam medis dengan benar, lengkap, dan tepat waktu (Hatta, 2017; Kemenkes RI, 2008).

Pengelolaan sistem penjajaran yang tidak sesuai akan menyebabkan missfile karena dipengaruhi oleh faktor sumber daya manusia, serta sarana dan prasarana yang ada (Mirna et al., 2011; T. G. Wati \& Nuraini, 2019). Sistem Penjajaran yang paling tepat untuk menghindari kesalahan dalam penjajaran (missfile) yaitu menggunakan sistem penjajaran berdasarkan 2 angka kelompok terakhir (Terminal Digit Filling System) (Sri Nani Purwaningrum etal, 2017; O. M. Wati et al., 2011).

Puskesmas sebagai penyedia sarana pelayanan kesehatan dituntut untuk memberikan pelayanan kesehatan yang cepat, tepat dan akurat. Oleh karena itu, puskesmas harus mampu mengelola rekam medis dengan baik sehingga rekam medis dapat disediakan dengan cepat dan tepat saat dibutuhkan.

Saat ini, Puskesmas Gondokusuman 2 Kota Yogyakarta sedang menerapkan sistem penjajaran rekam medis berbasis wilayah. Rekam medis disimpan berdasarkan kelurahan yang menjadi wilayah kerja Puskesmas. Khusus untuk pasien yang berasal dari luar daerah (luar wilayah kerja puskesmas), rekam medisnya akan disimpan menjadi satu tempat di rak rekam medis. Akan tetapi, dengan bertambahnya jumlah kunjungan pasien dari luar daerah, kapasitas tempat penyimpanan menjadi semakin terbatas. Penambahan rekam medis yang disimpan di satu section rak khususnya untuk pasien luar daerah semakin padat dan mulai tidak mencukupi. Menumpuknya rekam medis baik rekam medis aktif maupun inaktif berdampak pada ruangan penyimpanan rekam medis yang menjadi penuh, sehingga ruangan dan rak rekam medis tidak mampu lagi menyimpan rekam medis baru (Susanto et al., 2018). Hal ini yang melatarbelakangi tim Pengabdian Kepada Masyarakat (PKM) untuk membantu Puskesmas Gondokusuman 2 Kota Yogyakarta dalam melakukan perubahan sistem penjajaran rekam medis berdasarkan wilayah menjadi sistem angka akhir (Terminal Digit Filing system) yang memungkinkan rekam medis dapat disimpan tersebar ke dalam semua section rak penyimpanan.

\section{Metode}

Metode yang digunakan dalam kegiatan pengabdian kepada masyarakat ini dengan pendekatan difusi ipteks, berupa penyuluhan, pelatihan dan demonstrasi sistem penjajaran rekam medis serta pendampingan proses transformasi (perubahan) dari penjajaran rekam medis berdasarkan wilayah menjadi Terminal Digit Filing System (TDF). Dengan adanya kegiatan difusi ipteks tersebut diharapkan dapat meningkatkan pengetahuan masyarakat tentang sistem penjajaran rekam medis yang efektif untuk diterapkan di puskesmas. Kegiatan PKM dilaksanakan di Puskesmas Gondokusuman 2 Kota Yogyakarta, yang beralamat di Terban, Gondokusuman, Kota Yogyakarta, DIY. Kegiatan PKM ini melibatkan Pimpinan Tingkat Atas Puskesmas, Koordinator dan petugas rekam medis yang berjumlah sekitar 5 orang.

Pelaksanaan pengabdian ini merupakan bentuk implementasi kerjasama tridharma perguruan tinggi antara Prodi Rekam Medis dan Informasi Kesehatan (D-3) Fakultas Kesehatan Universitas Jenderal Achmad Yani dengan Prodi Manajemen Informasi Kesehatan (D-4) Sekolah Vokasi Universitas Gadjah Mada. Kegiatan PKM ini dilaksanakan dalam kurun waktu 3 (tiga) bulan dari bulan Oktober-Desember 2020. Berikut kegiatan difusi ipteks pada kegiatan PKM ini:

a. Tahap persiapan

Kegiatan diawali dengan observasi di unit kerja rekam medis Puskesmas Gondokusuman 2 Kota Yogyakarta. Identifikasi masalah dengan metode wawancara dilakukan kepada koordinator rekam medis Puskesmas Gondokusuman 2 Kota Yogyakarta. Selanjutnya, tim pengabdian kepada masyarakat mulai merumuskan masalah untuk selanjutnya disusun dalam bentuk proposal Pengabdian Kepada Masyarakat. Pengurusan ijin dilaksanakan demi kelancaran proses pengabdian kepada masyarakat. Mulai dari kegiatan observasi hingga perijinan ini berlangsung kurang lebih 2-3 minggu.

b. Tahap pelaksanaan

Pada tahap pelaksanaan pengabdian kepada masyarakat ini berlangsung kurang lebih 4-5 minggu dan dilaksanakan rangkaian kegiatan sebagai berikut:

1) Kegiatan penyuluhan dengan materi sistem penjajaran rekam medis yang disampaikan oleh Ketua Tim PKM dari Universitas Gadjah Mada. Tim PKM memberikan souvenir kepada peserta, 
guna meningkatkan keaktifan saat diskusi berlangsung.

2) Kegiatan dilanjutkan dengan pelatihan dan demontrasi cara penjajaran rekam medis dengan Terminal Digit Filing System oleh Ketua Tim PKM dari Universitas Jenderal Achmad Yani Yogyakarta. Tim PKM melatih satu persatu petugas rekam medis dengan metode role play dan masing-masing petugas rekam medis mencoba kembali mendemonstrasikan penjajaran rekam medis Terminal Digit Filing System.

3) Hibah pengadaan rak kayu terbuka diberikan guna mendukung keberhasilan transformasi dari sistem penjajaran wilayah menjadi Terminal Digit Filing System.

4) Selanjutnya dilakukan pendampingan pemindahan berkas rekam medis dari sistem penjajaran wilayah menjadi Terminal Digit Filing System.

c. Tahap akhir

Kegiatan pendampingan transformasi yang dilakukan pada tim Puskesmas Gondokusuman 2, yang semula kondisi awal sistem penjajaran rekam medis tersimpan penuh pada section kelompok wilayah tertentu menjadi tersebar secara merata ke seluruh section rak penyimpanan pada roll o' pack.

Bahan yang digunakan pada kegiatan pengabdian kepada masyarakat ini adalah handout sistem penjajaran rekam medis yang berisi materi yang berkaitan dengan proses transformasi sistem penjajaran Terminal Digit Filing yaitu rekam medis, sistem penyimpanan, sistem penomoran, sistem penjajaran, tracer dan retrieval rekam medis. Alat yang digunakan pada kegiatan PKM ini adalah laptop, jaringan internet, LCD, kamera, video, sound system, tracer, rekam medis dan roll o' pack.

\section{Hasil dan Pembahasan}

Kegiatan diawali dengan memberikan penyuluhan dengan sistem penjajaran rekam medis kepada Pimpinan Tingkat Atas Puskesmas, Koordinator dan petugas rekam medis yang berjumlah sekitar 5 orang (gambar 1). Hal ini dilatarbelakangi oleh pentingnya pemahaman pimpinan tingkat atas, koordinator dan petugas rekam medis pada penerapan sistem penjajaran rekam medis yang paling efektif dan efisien untuk diterapkan di puskesmas.

Sistem penjajaran merupakan sistem yang digunakan untuk melakukan penyimpanan rekam medis di dalam rak dengan cara dijajar. Berdasarkan cara penjajaran menurut nomor rekam medis, maka sistem penjajaran dapat dikelompokkan menjadi sistem nomor langsung (Straight Numerical Filing), sistem angka tengah (Middle Numerical Filing), dan sistem angka akhir (Terminal Digit Filing) (Lily Widjaja dan Deasy Rosmala Dewi, 2017; Sayles, 2013).

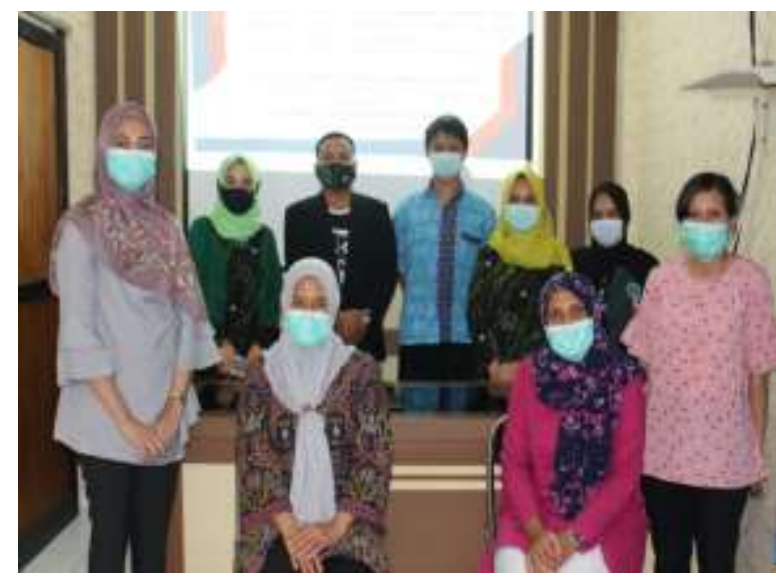

Gambar 1. Tim PKM bersama tim Puskesmas

Sistem penjajaran yang sangat disarankan adalah Terminal Digit Filing (TDF). Hal ini dikarenakan sistem TDF memudahkan dalam pengambilan dan penyimpanan kembali dokumen rekam medis ((O. M. Wati et al., 2011) dan menjaga kerahasiaan berkas rekam medis pasien (Hutama \& Santosa, 2016). Kelebihan lain dari sistem TDF adalah (a) pertambahan jumlah rekam medis yang tersebar merata ke seluruh rak penyimpanan; (b) petugas saat mengambil atau menyimpan kembali rekam medis tidak berdesak-desakan di satu tempat; (c) pekerjaan terbagi rata pada setiap section; (d) memudahkan pengambilan rekam medis inaktif; (e) penambahan jumlah rekam medis pada setiap section terkontrol sehingga dapat dihindari adanya rak kosong, memudahkan perencanaan peralatan penyimpanan rekam medis; (f) meminimalkan kekeliruan penyimpanan; (g) sistem TDF lebih efektif, efisien dan mudah diterapkan dibandingkan sistem SNF dan MDF (Hatta, 2017; Kornelia Aso, Sudalhar, 2019) .

Kegiatan pengabdian kepada masyarakat dilanjutkan dengan pelatihan dan demontrasi cara penjajaran TDF oleh Ketua Tim PKM dari Universitas Jenderal Achmad Yani Yogyakarta. Tim PKM melatih satu persatu petugas rekam medis dengan metode role play dan masing-masing petugas rekam medis mencoba kembali mendemonstrasikan cara penjajaran TDF (gambar 2). 


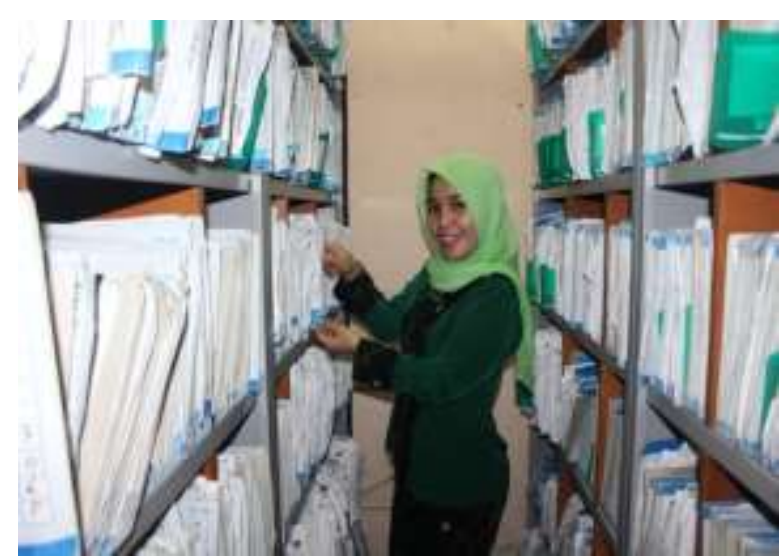

Gambar 2. Demontrasi sistem penjajaran Terminal Digit Filing

Penjajaran rekam medis dengan sistem TDF dilakukan dengan cara petugas melihat dua digit angka secara bertahap, dimulai dua digit angka primer (terakhir) untuk menemukan letak rak penyimpanan selanjutnya melihat angka sekunder (kedua) untuk menemukan sub rak dan diakhiri dengan angka tersier (ketiga) untuk menyimpan rekam medis. Cara penjajaran TDF tersebut meminimalkan kekeliruan penyimpanan (Anwar et al., 2019; Hatta, 2017) Sedangkan menurut (Ningsih et al., 2020) disampaikan bahwa Terminal Digit Filing System beresiko terjadinya kesalahan pengambilan rekam medis pada saat proses pencarian rekam medis lama apabila fasilitas pelayanan kesehatan tidak tertib dalam menggunakan tracer.

Kegiatan pengabdian masyarakat ini dilakukan dengan menyediakan rak penyimpanan yang digunakan untuk menyekat roll o pack yang ada di Puskesmas. Rak terbuat dari kayu dengan ukuran $60 \times 35 \times 27 \mathrm{~cm}$ sebanyak 40 unit (gambar 3).

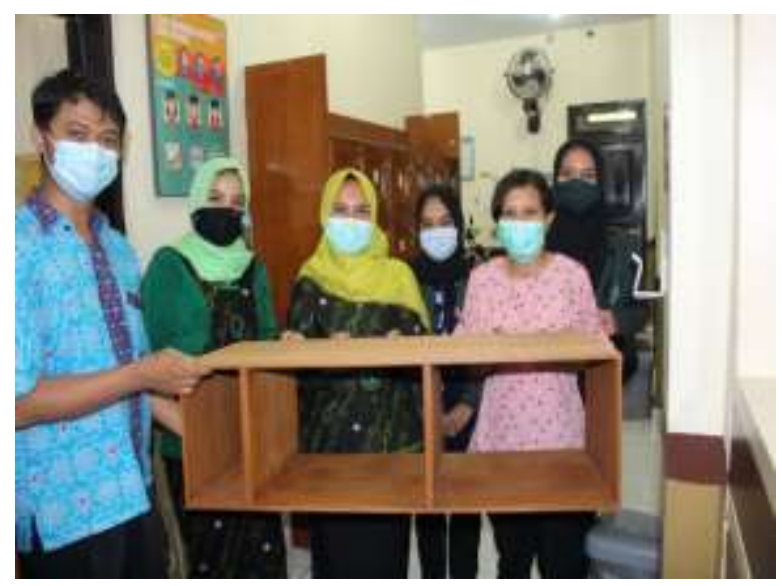

Gambar 3. Penyerahan rak penyimpanan
Rak terbuka (open self file unit), dan roll o' pack yang berbahan kayu atau besi merupakan alat penyimpanan dokumen rekam medis yang umum dipakai (Budi., 2011), dan penambahan rak kayu diperlukan untuk mencegah rekam medis agar tidak tercecer (Anwar et al., 2019). Rak kayu tersebut kemudian dimasukkan ke dalam shaft pada roll o'pack yang berfungsi sebagai pemisah (sekat) antar-seksi penjajaran rekam medis (gambar 4).

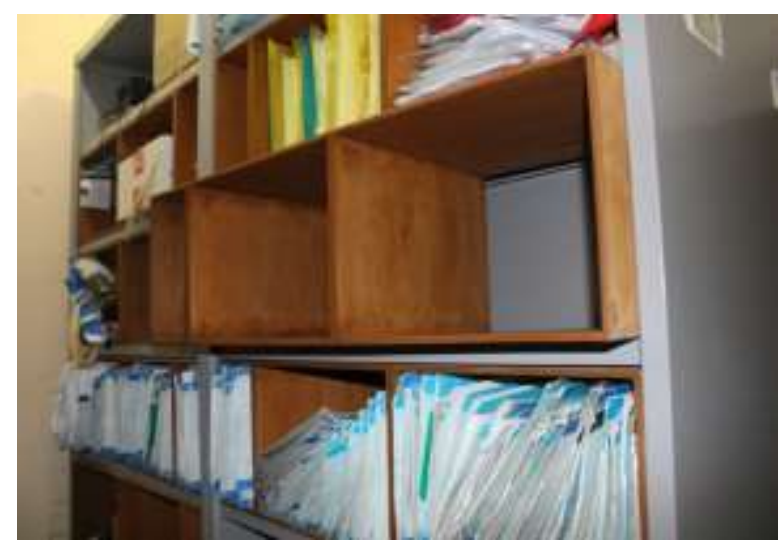

Gambar 4. Pemasangan rak kayu di roll o' pack

Setelah rak kayu selesai dibuat dan dipasang pada roll o'pack, kegiatan selanjutnya adalah proses perubahan sistem penyimpanan berdasarkan penjajaran dari berbasis wilayah menjadi Terminal Digit Filing System (TDF). Proses perubahan sistem dibarengi dengan pendampingan terhadap petugas oleh tim pengabdian kepada masyarakat (gambar 5). Hal ini dilakukan agar petugas mengenal sistem yang diberlakukan dan berkompeten untuk melaksanakan dan mengelola sistem penyimpanan yang baru.

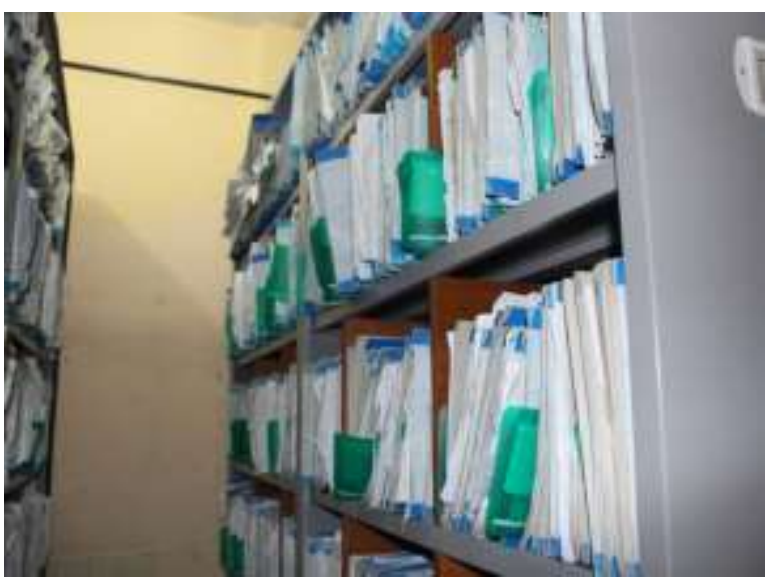

Gambar 5. Rekam medis sudah dijajarkan dengan sistem TDF 


\section{Simpulan dan Saran}

Kegiatan pengabdian ini berupa difusi ipteks pada transformasi sistem penjajaran rekam medis menggunakan Terminal Digit Filing di Puskesmas Gondokusuman 2 Kota Yogyakarta. Kegatan ini dilakukan sebagai bentuk pengabdian untuk membantu Puskesmas Gondokusuman 2 Kota Yogyakarta dalam hal persiapan, pengadaan rak kayu dan pendampingan pada saat dilakukan transformasi (perubahan) sistem penjajaran rekam medis dari berdasarkan wilayah menjadi sistem angka akhir (Terminal Digit Filing), sebagai akibat dari tuntutan kebutuhan sistem penjajaran rekam medis secara merata pada seluruh section rak penyimpanan dan keterbatasan ruang penyimpanan. Hasil pengabdian ini adalah penerapan Terminal Digit Filing yang mampu menyimpan rekam medis tersebar ke dalam semua section rak penyimpanan. Peningkatan efisiensi dan efektivitas kegiatan penjajaran rekam medis di Puskesmas Gondokusuman 2 Kota Yogyakarta ditandai dengan kerapian penjajaran rekam medis yang tersebar secara merata pada seluruh section sehingga memudahkan pembagian tugas dan tanggung jawab petugas rekam medis di kelompom section dan terciptanya kemudahan petugas rekam medis dalam menemukan kali rekam medis pasien lama.

Keterbatasan kegiatan PKM ini adalah hanya sampai pada proses transformasi perubahan dari sistem wilayah menjadi TDF. Sehingga diharapkan pada program PKM berikutnya dapat melaksanakan program evaluasi dan monitoring transformasi sistem penjajaran TDF untuk menjamin keberhasilan proses transformasi.

\section{Ucapan Terima Kasih}

Kami ucapkan terima kasih kepada Program studi Rekam Medis dan Informasi Kesehatan Univresitas Jenderal Achmad Yani Yogyakarta yang telah mendukung kegiatan ini, dan Program Studi Manajemen Informasi Kesehatan Sekolah Vokasi Universitas Gadjah ada yang menjadi mitra pada kegiatan pengabdian kepada masyarakat di Puskesmas Gondokusuman 2 Kota Yogyakarta.

\section{Daftar Pustaka}

Anwar, A. C., Anggryani, F., \& Juwita, R. (2019). Analisa mutu sistem penyimpanan dokumen rekam medis di rumah sakit umum pindad turen. Prosiding Call For Paper SMIKNAS, 116-124.
Budi., S. C. (2011). Manajemen Unit Kerja Rekam Medis. Yogyakarta. Quantum Sinergis Media.

Hatta, G. R. (2017). Pedoman Manajemen Informasi Kesehatan di Sarana Pelayanan Kesehatan. Universitas Indonesia.

Hutama, H., \& Santosa, E. (2016). Evaluasi Mutu Rekam Medis Di Rs Pku 1 Muhammadiyah Yogyakarta: Studi Kasus Pada Pasien Sectio Caesaria. Jurnal Medicoeticolegal Dan Manajemen Rumah Sakit, 5(1), 25-34. https://doi.org/10.18196/jmmr.5103

Kemenkes RI. (2008). Pemenkes 269/PER/III/2008 tentang Rekam Medis. In Kemenkes RI (pp. 1-7).

Kornelia Aso, Sudalhar, T. W. Y. P. (2019). Tinjauan Pelaksanaan Sistem Penjajaran Dokumen Rekam meids Pada Bagian Filing UPTD Puskesmas Bojonegoro. Jurnal Hpospita Science, 3(1), 103-108.

Lily Widjaja dan Deasy Rosmala Dewi. (2017). Manajemen Informasi Kesehatan II: Sistem dan Sub Sistem Pelayanan RM. In Bahan Ajar RMIK. PPSDM Kemenkes.

Mirna, R., Lestari, T., \& Mulyono, S. (2011). Tinjauan Pelaksanaan Sistem Penjajaran Dokumen Rekam Medis Di Ruang Filling Rumah Sakit Umum Daerah Dr. R. Soedjati Soemodiharjo Kabupaten Grobogan. Jurnal Kesehatan, V(2), 66-82.

Ningsih, K. P., Tunnisa, U., \& Erviana, N. (2020). Manajemen Resiko Redesign Sistem Penjajaran Rekam Medis dengan Metode Failure Mode and Effect Analysis ( FMEA ). Indonesian of Health Management Journal, 8(1), 8-20.

Sayles, N. B. (2013). Health Information Management Technology:An applied approach.American Health Information Management Association. 4 Ed.

Sri Nani Purwaningrum etal. (2017). Rancangan Manajmen Filing Dan Desain Formulir Pelayanan Kesehatan Umum Di Puskesmas Sunyaragi Kota Cirebon. Jurnal Pengabdian Kepada Masyarakat Poltekkes Kemenkes Tasikmalaya, 1-7.

Susanto, E., Windari, A., Irmawati, I., Risyanti, I. P., Prakoso, Y. T., Akbar, J. A., Nugroho, R. F., Krisnanita, A. I., \& Kristiyani, B. R. (2018). Retensi Rekam Medis Dalam Upaya Efisiensi Rak Penyimpanan. Link, 14(2), 106. https://doi.org/10.31983/link.v14i2.3770 
Jurnal LINK, 17 (1), 2021, 66 - 66

DOI: 10.31983/link.v17i1.6819

Wati, O. M., Pujihastuti, A., \& Riyoko. (2011) Tinjauan Pelaksanaan Penyimpanan dan Penjajaran Dokumen Rekam Medis di Ruang Filing RSUD Dr Moewardi. Jurnal Kesehatan, V(2), 20-28.
Wati, T. G., \& Nuraini, N. (2019). Analisis Kejadian Missfile Berkas Rekam Medis Rawat Jalan di Puskesmas Bangsalsari Try. Rekam Medik Dan Informasi Kesehatan, 1(1), 23-30. 